\title{
Mass spectrometry characterization of peroxycarboxylic acids as proxies for reactive oxygen species (ROS) and highly oxygenated molecules (HOMs) in atmospheric aerosols
}

\author{
Sarah S. Steimer, Ivan Kourtchev ${ }^{\S}$, Markus Kalberer* \\ Department of Chemistry, University of Cambridge, Cambridge, CB2 1EW, United Kingdom
}

A significant fraction of atmospheric aerosol particles is composed of organic material with a highly complex but poorly characterized composition. For a better understanding of aerosol effects and processes in the atmosphere a more detailed knowledge of aerosol components at a molecular level is needed. Peroxy acids might play a significant role in particle toxicity, due to their oxidizing properties, and they were recently found to be involved in particle formation. Due to the lack of appropriate standards the identification and quantification of peroxy acids is often highly uncertain. Mass spectrometry (MS) is a powerful tool to characterize unidentified compounds in complex mixtures. However, so far there is only little information regarding the ionization and fragmentation behavior of peroxy acids in mass spectrometers. To study their fragmentation patterns, we synthesized 12 peroxy acids with $\mathrm{C}_{8}$ to $\mathrm{C}_{10}$ carbon backbones and mono- or diperoxy acid functionality. The peroxy acids were separated using liquid chromatography, detected via negative mode electrospray ionization high resolution MS and their fragmentation patterns (MS/MS spectra) were identified. The MS/MS spectra of the peroxy acids showed fragmentation patterns clearly different from the corresponding acid, with a strong similarity between compounds of different chain length but analogous functional groups. Neutral loss of $\mathrm{CH}_{2} \mathrm{O}_{2}$ was observed for all investigated linear peroxy acids, but not for carboxylic acids and could therefore serve as a diagnostic ion for peroxy acids. The obtained results are a large step towards unambiguous characterization of peroxy acids in the atmosphere.

\section{INTRODUCTION}

A large number of epidemiological studies show that ambient aerosols are correlated with a wide range of respiratory and cardio-vascular diseases. ${ }^{1-3}$ It is not known which particle components cause these negative health effects, but reactive oxygen species (ROS), a term summarizing various oxidizing compounds, are hypothesized to be a main contributor to the toxicity of particles in ambient air. ${ }^{4,5}$ An example of this is the strong oxidative potential of isoprene-derived hydroxyhydroperoxide. ${ }^{6}$ Peroxy acids are a subtype of ROS suggested to be present in secondary organic aerosol $(\mathrm{SOA})^{7,8}$ and therefore potentially relevant for particle toxicity. It was recently shown that compounds with multiple hydroperoxy and peroxy acid groups (also termed highly oxygenated molecules', HOMs), formed via autoxidation in the gas phase, are strongly involved in the initial stages of SOA formation ${ }^{9,10}$. Because there are no standards available for HOMs, their characterization and quantification remains challenging.

Apart from their relevance for atmospheric science, peroxy acids are used as reagents in synthetic chemistry, e.g. in Baeyer-Villiger oxidations, ${ }^{11}$ and find wide industrial application as disinfectants and bleaching agents. ${ }^{12-16}$ Given the multitude of industrial applications of peroxy acids, a wide range of methods have been developed for their analysis, including iodometry, ${ }^{17}$ spectrophotometry ${ }^{18}$ and different chromatographic methods such as gas chromatography with flame ionization detection ${ }^{19}$ or high performance liquid chromatography (HPLC) with postcolumn derivatization followed by UV/VIS detection. ${ }^{20}$ When unspecific detectors such as UV/VIS detectors are used, authentic standards are needed to get an unambiguous identification of the analyte. This presents a problem for the analysis of atmospheric aerosols, which can contain thousands of different organic compounds for which standards are rarely commercially available.

Mass spectrometry and especially MS/MS analyses in principle provide powerful tools to characterize peroxy acids in organic aerosol without the need of an authentic standard. While there are several papers describing the use of MS to detect the presence of peroxyacetic acid in the gas phase, ${ }^{21-23}$ there are only few MS measurements of any other peroxy acids, and usually MS/MS is not 
utilized. ${ }^{24,25}$ A few other studies describe the mass spectrometry detection of peroxy acids in particulate matter based on elemental composition and observed fragmentation; however, without confirmation from authentic standards. ${ }^{7,8}$ To the best of our knowledge, there is only one systematic study of peroxy acid MS/MS fragmentation ${ }^{26}$, which focusses on aromatic peroxy acids, which are of limited relevance considering the type of peroxy acids thought to be present in SOA.

Our study aims to fill this gap and provide insight into general and characteristic fragmentation patterns of atmospherically relevant organic peroxy acids to provide a method of identifying unknown peroxy acids in highly complex organic mixtures. We have synthesized 12 aliphatic compounds with peroxy acid functionalities: the peroxy acid analogues of the straight-chain saturated $\mathrm{C}_{8}-\mathrm{C}_{10}$ monocarboxylic acids, the mono- and diperoxy acid derivatives of the corresponding dicarboxylic acids and two cyclic monoperoxy dicarboxylic acids. The compounds were separated by HPLC and their fragmentation patterns were studied using ESI-MS/MS in negative mode with collision induced fragmentation (CID).

\section{EXPERIMENTAL SECTION}

\section{Safety considerations}

The syntheses described in this paper are strongly exothermic. Additionally, peroxymonosulfuric acid (Caro's acid), which is explosive and an extremely strong oxidizer, is generated as a by-product. Pure peroxy acids and their concentrated solutions themselves may cause severe explosions. They are also strong oxidizers and need to be kept away from easily oxidizable materials. Appropriate safety precautions need to be taken when working with peroxy acids and the quantity of material handled should be kept to a minimum.

\section{Chemicals}

Sulfuric acid $\left(\mathrm{H}_{2} \mathrm{SO}_{4}, 95-98 \%\right)$, caprylic acid (octanoic acid, $\mathrm{C}_{8} \mathrm{H}_{16} \mathrm{O}_{2}, \geq 99 \%$ ), pelargonic acid (nonanoic acid, $\mathrm{C}_{9} \mathrm{H}_{18} \mathrm{O}_{2}, \geq 97 \%$ ), capric acid (decanoic acid, $\mathrm{C}_{10} \mathrm{H}_{20} \mathrm{O}_{2}$, $\geq 98 \%$ ), suberic acid (octanedioic acid, $\mathrm{C}_{8} \mathrm{H}_{14} \mathrm{O}_{4}, \geq 98 \%$ ), azelaic acid (nonanedioic acid, $\mathrm{C}_{9} \mathrm{H}_{16} \mathrm{O}_{4}, 98 \%$ ), sebacic acid (decanedioic acid, $\left.\mathrm{C}_{10} \mathrm{H}_{18} \mathrm{O}_{4}, 99 \%\right)$ and hydrogen peroxide $\left(\mathrm{H}_{2} \mathrm{O}_{2}, 50 \%\right.$, stabilized) were purchased from Sigma-Aldrich. D(+)Camphoric acid $((1 R, 3 S)-1,2,2$-trimethyl-1,3cyclopentanedicarboxylic acid, $\mathrm{C}_{10} \mathrm{H}_{16} \mathrm{O}_{4}, 99 \%$ ) was purchased from Acros Organics. All carboxylic acids were used without further purification. Acetonitrile, formic acid and water, all in OPTIMA ${ }^{\circledR}$ LC/MS grade, were purchased from Fisher Scientific.

\section{Synthesis}

The synthesis of peroxycaprylic acid (peroxyoctanoic acid, $\mathrm{C}_{8} \mathrm{H}_{16} \mathrm{O}_{3}$ ), peroxypelargonic acid (peroxynonanoic acid, $\mathrm{C}_{9} \mathrm{H}_{18} \mathrm{O}_{3}$ ) and peroxycapric acid (peroxydecanoic acid, $\mathrm{C}_{10} \mathrm{H}_{20} \mathrm{O}_{3}$ ) was adapted from Parker et al. ${ }^{27}$ The synthesis of monoperoxysuberic acid (monoperoxyoctanedioic acid, $\mathrm{C}_{8} \mathrm{H}_{14} \mathrm{O}_{5}$ ), diperoxysuberic acid (diperoxyoctanedioic acid, $\mathrm{C}_{8} \mathrm{H}_{14} \mathrm{O}_{6}$ ), monoperoxyazelaic acid (monoperoxynonanedioic acid, $\mathrm{C}_{9} \mathrm{H}_{16} \mathrm{O}_{5}$ ), diperoxyazelaic acid (diperoxynonanedioic acid, $\mathrm{C}_{9} \mathrm{H}_{16} \mathrm{O}_{6}$ ), monoperoxysebacic acid (monoperoxydecanedioic acid, $\mathrm{C}_{10} \mathrm{H}_{18} \mathrm{O}_{5}$ ) and diperoxysebacic acid (diperoxydecanedioic acid, $\mathrm{C}_{10} \mathrm{H}_{18} \mathrm{O}_{6}$ ) was based on the procedure by Parker et al. ${ }^{28}$ The same procedure was employed for the synthesis of monoperoxycamphoric acid $\left(\mathrm{C}_{10} \mathrm{H}_{16} \mathrm{O}_{5}\right)$. The chemical structures of the different peroxy acids are shown in Figure S-1.

To synthesize the peroxy acids, the corresponding carboxylic acid was dissolved under stirring in concentrated sulfuric acid (95-98\%) in an open beaker. The resulting solution was cooled in an ice water bath to $10-15^{\circ} \mathrm{C}$. Under constant stirring, $50 \% \mathrm{H}_{2} \mathrm{O}_{2}$ was slowly added dropwise over $\sim 5$ min (see Table S-1). A white precipitate forms in all cases.

For the monocarboxylic acid derived peroxy acids, the reaction mixture was continuously stirred for a total of $60 \mathrm{~min}$ reaction time with the vessel slowly warming to room temperature. Thereafter, $3 \mathrm{ml}$ of $4^{\circ} \mathrm{C}$ water were added to the reaction vessel and the same volume of liquid removed again using a pipette to wash the solution. This step was repeated twice. The remaining precipitate and solution were then dissolved in $10 \mathrm{ml}$ 20/80 water/acetonitrile.

For the dicarboxylic acid derivatives, the reaction was continued for a total of $180 \mathrm{~min}$ with the vessel slowly warming to room temperature. The addition of $4 \mathrm{ml}$ half-saturated ammonium sulfate solution $\left(4^{\circ} \mathrm{C}\right)$ to the reaction mixture for washing resulted in a finely dispersed precipitate in the liquid phase which did not readily settle and which made repeated washing steps impossible. Therefore, $10 \mathrm{ml} \mathrm{20/80} \mathrm{water/acetonitrile}$ were directly added to the solution to dissolve the precipitate. Two phases form, of which the upper one (acetonitrile phase) is used for analysis. The syntheses result in product solutions containing both mono- and diperoxydicarboxylic acids.

The exact quantities of chemicals used in the syntheses are shown in Table S-1. The product solutions were stored in a freezer at $-22^{\circ} \mathrm{C}$.

\section{Analysis}

Direct injection ESI-MS/MS was performed to optimize instrument conditions. For this, each product solution was diluted by a factor 100 with 50/50 water/acetonitrile and measured separately. For peroxycapric acid, two additional solutions in different solvents $(100 \%$ acetonitrile and $50 / 50 \quad 0.1 \%$ formic acid/acetonitrile) were prepared to test the influence of solvent on the ionization of the mononcaboxylic acid 
derived peroxyacids. Two different analyte solutions were prepared for HPLC-MS analysis. The first solution was a mixture of the products from the monocarboxylic acid based syntheses, diluted by factor 100 with $50 / 50$ water/acetonitrile. The second solution contained the products of the four dicarboxylic acid based syntheses, diluted by a factor 100 in $80 / 20$ water/acetonitrile. The mixtures were analyzed using HPLC-ESI-MS. The HPLC was an Accela system (Thermo Scientific, San Jose, USA) equipped with a T3 Atlantis C18 column (3 $\mu \mathrm{m} ; 3.0 \times 150 \mathrm{~mm}$; Waters, Milford, USA). A highresolution LTQ Orbitrap Velos mass spectrometer (Thermo Scientific, Bremen, Germany), equipped with a heated electrospray ionization (HESI) source, was used as the detector.

\section{HPLC separation}

The monocarboxylic acids and their peroxy acid derivatives were separated using gradient elution with a flow rate of $200 \mu \mathrm{L} / \mathrm{min}$. The mobile phase was composed of a mixture of three solvents: $0.1 \%$ formic acid in water (solvent A), acetonitrile (solvent B) and water (solvent $\mathrm{C}$ ). The initial mobile phase composition of $90 \% \mathrm{~A}$ and $10 \% \mathrm{~B}$ was maintained for $5 \mathrm{~min}$. Solvent A was then linearly decreased to $0 \%$ over $3 \mathrm{~min}$, while $\mathrm{B}$ and $\mathrm{C}$ increased to $50 \%$ each. After this, B was increased further to $90 \%$ over $11 \mathrm{~min}$, accompanied by a decrease in $\mathrm{C}$ to $10 \%$. This composition was kept for $1 \mathrm{~min}$. During the subsequent $3 \mathrm{~min}$, solvent $\mathrm{A}$ was increased to $63 \%$, while $\mathrm{B}$ was reduced to $37 \%$ and $\mathrm{C}$ to $0 \%$. A was then further increased to $90 \%$ and $\mathrm{B}$ decreased to $10 \%$ over $3 \mathrm{~min}$. This composition was maintained for the last $5 \mathrm{~min}$. Formic or acetic acid are often used as additives in HPLC to improve the retention and peak shape of acidic species. It was found that addition of formic or acetic acid led to strong suppression of the signals from deprotonated peroxy acid molecules in both direct injection and HPLC-MS even at low concentrations $(0.01 \%-0.1 \%)$. The chromatographic method was therefore developed to minimize presence of formic acid during the elution time of the peroxy acids. This improved the signal intensity by about 1.5 orders of magnitude.

To separate the dicarboxylic acids and their peroxy acid derivatives, gradient elution was carried out at a flow rate of $200 \mu \mathrm{L} / \mathrm{min}$ with a mobile phase composed of only solvent $\mathrm{A}$ and $\mathrm{B}$ in varying composition. The starting concentration of $15 \% \mathrm{~B}$ was held constant for two minutes and then raised to $32.4 \%$ over $20 \mathrm{~min}$. After an increase of $\mathrm{B}$ to $90 \%$ during the following 11 min segment, it was reduced back to $15 \%$ within $5 \mathrm{~min}$ and held at this concentration for an additional $10 \mathrm{~min}$.

\section{MS}

The instrument was calibrated using Pierce ${ }^{\circledR}$ ESI Negative Ion Calibration Solution (Thermo Scientific, Rockford, USA. measurements were carried out in negative ionization mode. For direct injection, the source settings were: spray voltage -3.1 to $-3.7 \mathrm{kV}$, source heater temperature $150^{\circ} \mathrm{C}$, capillary temperature $275^{\circ} \mathrm{C}$, sheath gas flow 12 arbitrary units, auxiliary gas flow 5-7 arbitrary units, no sweep gas flow and S-lens RF level $60 \%$. The sample flow rate was $9-18 \mu \mathrm{L} / \mathrm{min}$. The following source parameters were used for HPLC: spray voltage $-3.2 \mathrm{kV}$, source heater temperature $250^{\circ} \mathrm{C}$, capillary temperature $275^{\circ} \mathrm{C}$, sheath gas flow 40 arbitrary units, auxiliary gas flow 10 arbitrary units, no sweep gas flow and S-lens RF level 55\%. mass spectra for the HPLC-MS measurements were collected in full scan mode over a mass range of $m / z \quad 100-650$, using the lock mass of the deprotonated dimer of formic acid at $\mathrm{m} / \mathrm{z} 91.0037$ and a resolution of 100000 at $\mathrm{m} / \mathrm{z} 400$. Parallel MS/MS scans were performed using a global mass list, with a resolution of 60000 , a mass range of $m / z 50-300$ and three different isolation widths (1.0, 1.5 and 2.0) for comparison. CID was used for ion fragmentation; the energies used for the different precursor ions are given in Table 1 and Table 2. Direct infusion measurements were used to optimize this CID method.

\section{Data evaluation}

The Thermo Xcalibur 2.2 software was used for data evaluation. The assignment of elemental composition had a mass tolerance of $6 \mathrm{ppm}$. For the investigation of MS/MS fragmentation, the mass list contains all $\mathrm{m} / \mathrm{z}$ smaller than the precursor ion which have a relative abundance above the chosen threshold, usually $>1 \%$. The same procedure was then repeated with a background subtracted version of the spectrum. The final list of product ions is based on the background subtracted mass list, but additionally excludes $\mathrm{m} / \mathrm{z}$ which did not have an assigned elemental composition, which could be dismissed as product ions based on the assigned elemental composition or whose extracted ion chromatogram showed a poor overlap with the base peak chromatogram of the MS/MS measurement. While the selection of product ions and their relative abundance was based on the background subtracted mass list, the masses were taken from the raw data, which shows higher mass accuracy.

\section{RESULTS AND DISCUSSION}

\section{Liquid chromatography separation of carboxylic acids and peroxy acids}

The three monocarboxylic acids and their three peroxy acid derivatives were clearly separated using the HPLC method described above (Figure 1). The three monocarboxylic acids elute about 1-1.5 minutes before their corresponding peroxy acids due to their higher polarity. Peaks were assigned based on presence of the deprotonated analyte molecule $\left([\mathrm{M}-\mathrm{H}]^{-}\right)$. 


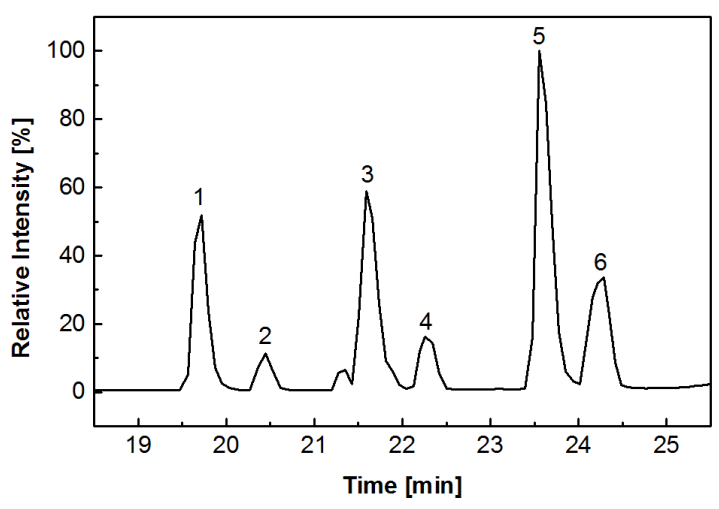

Figure 1. Base peak chromatogram showing the separation of three monocarboxylic acids and their corresponding peroxy acid analogues: caprylic acid (1), peroxycaprylic acid (2), pelargonic acid (3), peroxypelargonic acid (4), capric acid (5) and peroxycapric acid (6).

The base peak chromatogram of the separation of dicarboxylic acids and their derivatives shows 12 peaks in the region of interest (Figure 2). The peaks are well separated with the exception of diperoxysuberic acid and camphoric acid, which show a slight overlap (peaks 3 and 4). The only peroxy acid that could not be synthesized with the method described here was diperoxycamphoric acid. The extracted ion chromatogram of the monoperoxycamphoric acid mass (Figure S-2) shows two peaks: a large peak equivalent to peak 6 in Figure 2 and a smaller peak at an earlier retention time equivalent to the small peak 5 in Figure 2. This peak's area is about 16 times smaller than that of the larger peak 6 . It shows the same major product ions as peak 6, unambiguously identified as monoperoxycamphoric acid, and is therefore likely the other monoperoxycamphoric acid isomer. For the more commonly applied synthesis of monoperoxycamphoric acid from camphoric acid anhydride, 3peroxycamphoric acid is dominant. ${ }^{29}$ Pirkle and Rinaldi $^{30}$ found a 15:1 mixture of the two isomers, supporting our findings.

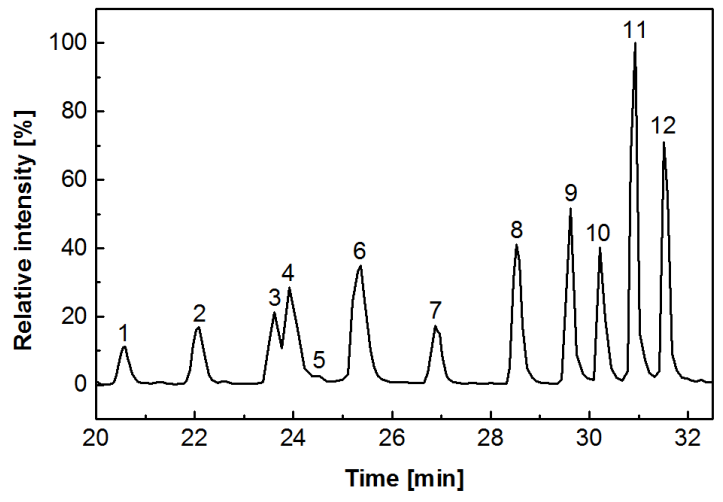

Figure 2. Base peak chromatogram showing the separation of four dicarboxylic acids and their corresponding peroxy acid analogues: suberic acid (1), monoperoxysuberic acid (2), diperoxysuberic acid (3), camphoric acid (4), monoperoxycamphoric acid $(5,6)$, azelaic acid (7), monoperoxyazelaic acid (8), diperoxyazelaic acid (9), sebacic acid (10), monoperoxysebacic acid (11) and diperoxysebacic acid (12).

\section{Mass spectrometry analyses}

Extracted ion chromatograms show that all acids and the synthesized peroxy acids are detected in form of their $[\mathrm{M}-\mathrm{H}]^{-}$ions. The chromatographic peaks of both mono- and diperoxycarboxylic acids additionally show the presence of the corresponding carboxylic acid [M$\mathrm{H}]^{-}$. In case of the diperoxycarboxylic acids, the [M-H] of the corresponding monoperoxy acid is observed as well. An example of the apparent co-elution of acid and peroxy acid can be seen in Figure 3 for the monocarboxylic acids and their corresponding peroxy acids. The extracted ion chromatograms for the dicarboxylic acids and their peroxy acid derivatives are shown in Figure S-3. The ratio of monoperoxy acid to carboxylic acid $[\mathrm{M}-\mathrm{H}]^{-}$signal within the monoperoxy acid chromatographic peak ranges from 0.42 to 0.98 for the monocarboxylic acids and 13.30 to 20.09 for the dicarboxylic acids. The ratio of diperoxy acid to carboxylic acid signal in the diperoxy acid peak ranges from 0.13 to 0.15 , while the range of diperoxy acid to monoperoxy acid signal is 1.90 to 2.33 . Harman et al. ${ }^{26}$ made similar observations for peroxybenzoic acid. It is well known that electrochemical processes occurring in ESI can significantly influence the observed mass spectra. ${ }^{31-33}$ Peroxy acids are electrochemically active $^{24,34}$ and Awad et al. ${ }^{35}$ concluded that the electroreduction of peroxyacetic acid proceeds as a twostep electron transfer mechanism which results in formation of the acetate ion. Therefore, electroreduction seems to be a likely cause for the observed presence of $[\mathrm{M}-\mathrm{H}]^{-}$ions from reduced compounds in the peroxy acid peaks in our samples.

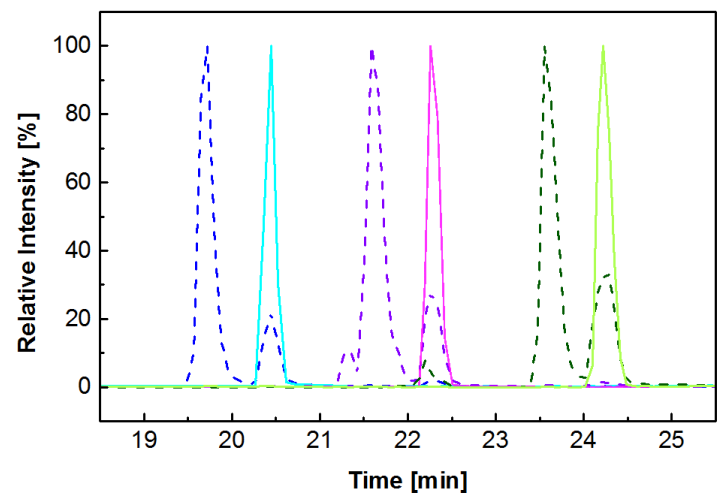

Figure 3. Extracted ion chromatograms for the $[\mathrm{M}-\mathrm{H}]^{-}$ions of caprylic acid (blue dashed line), peroxycaprylic acid 
(cyan solid line), pelargonic acid (purple dashed line), peroxypelargonic acid (magenta solid line), capric acid (dark green dashed line) and peroxycapric acid (bright green solid line).

\section{MS/MS of monocarboxylic acids and their derivatives}

The MS/MS spectra of the three monocarboxylic acids show loss of water as the only fragmentation pathway (Table 1). The signal intensity of the detected [M-H$\mathrm{H}_{2} \mathrm{O}$ ] product ions is low compared to the abundance of the respective precursor ion both in the mass spectra, and the MS/MS spectra at $0 \mathrm{eV}$ collision energy. This is in good agreement with the results from a study e.g. by Št'ávová et al., ${ }^{36}$ who found [M-19] to be the only observed product ion for monocarboxylic acid MS/MS and reported difficulties in obtaining an efficient fragmentation. These results suggest that the main fragmentation pathway of the monocarboxylic acid [M$\mathrm{H}]^{-}$leads to formation of small product ions below the $\mathrm{m} / \mathrm{z}$ range of our mass spectrometer, which therefore are not detected.

Fragmentation of all three peroxyacid $[\mathrm{M}-\mathrm{H}]^{-}$ precursor ions shows the same two neutral losses: $\mathrm{CH}_{2} \mathrm{O}_{2}$ (or $\mathrm{CO}+\mathrm{H}_{2} \mathrm{O}$ ) and $\mathrm{H}_{2} \mathrm{O}$ (Table 1). The product ion spectra are dominated by $\left[\mathrm{M}-\mathrm{H}-\mathrm{CH}_{2} \mathrm{O}_{2}\right]^{-}$ions, while $\left[\mathrm{M}-\mathrm{H}-\mathrm{H}_{2} \mathrm{O}\right]^{-}$only gives rise to a minor signal of a few percent relative intensity. The only saturated peroxycarboxylic acid investigated by Harman et al., ${ }^{26}$ peroxycyclohexylcarboxylic acid, shows loss of nominal mass 46 as the main fragmentation pathway. This neutral loss is interpreted as a likely stepwise or concerted loss of $\mathrm{CO}$ and $\mathrm{H}_{2} \mathrm{O}$, which agrees well with our observations. It was absent from the product ion spectrum of the aromatic analogue ${ }^{26}$. Compared to the aliphatic peroxymonocarboxylic acids measured in our study, peroxycyclohexylcarboxylic acid shows a much wider spectrum of additional product ions ${ }^{26}$, a difference which could be explained by its cyclic structure.

\section{MS/MS of dicarboxylic acids and their derivatives}

For the three linear dicarboxylic acids, a combined loss of $\left(\mathrm{CO}_{2}+\mathrm{H}_{2} \mathrm{O}\right.$ or $\left.\mathrm{CH}_{2} \mathrm{O}_{3}\right)$ was the dominant fragmentation process (Table 2). This is in agreement with the observations made e.g. by Grossert et al. ${ }^{37}$ in their detailed study of dicarboxylic acid fragmentation. Consistent as well is the fact that the only other neutral losses observed were $\mathrm{CO}_{2}$ or $\mathrm{H}_{2} \mathrm{O}$. The combined loss of $\left(\mathrm{CO}_{2}+\mathrm{H}_{2} \mathrm{O}\right)$ was also found to be an important process in the fragmentation of atmospherically relevant linear terpenoic acids, such as 3-methyl-1,2,3butanetricarboxylic acid (MBTCA) and homoterpenylic Table 1. MS/MS fragmentations of [M-H] ${ }^{-}$ions from monocarboxylic acids and their peroxyacid analogues. ${ }^{1}$

\begin{tabular}{|l|l|l|l|l|l|}
\hline Compound & Deprotonated & $m / z$ & Collision & product ion $m / z$ & neutral loss(es) \\
\hline
\end{tabular}

\footnotetext{
${ }^{1}$ The data shown were averaged from four spectra measured with an isolation width of 1.0.
} 


\begin{tabular}{|l|l|l|l|l|l|}
\hline & molecule $[\mathrm{M}-\mathrm{H}]^{-}$ & $(\Delta \mathrm{ppm})$ & $\begin{array}{l}\text { energy } \\
(\%)\end{array}$ & ${\text { (rel. abund. })^{2}}$ & \\
\hline Caprylic acid & {$\left[\mathrm{C}_{8} \mathrm{H}_{15} \mathrm{O}_{2}\right]^{-}$} & $143.10768(-0.493)$ & 28 & $125.09719(100)$ & $\mathrm{H}_{2} \mathrm{O}$ \\
\hline Pelargonic acid & {$\left[\mathrm{C}_{9} \mathrm{H}_{17} \mathrm{O}_{2}\right]^{-}$} & $157.12327(-0.847)$ & 30 & $139.11283(100)$ & $\mathrm{H}_{2} \mathrm{O}$ \\
\hline Capric acid & {$\left[\mathrm{C}_{10} \mathrm{H}_{19} \mathrm{O}_{2}\right]^{-}$} & $171.13860(-2.633)$ & 32 & $153.12844(100)$ & $\mathrm{H}_{2} \mathrm{O}$ \\
\hline Peroxycaprylic acid & {$\left[\mathrm{C}_{8} \mathrm{H}_{15} \mathrm{O}_{3}\right]^{-}$} & $159.10267(0.015)$ & 26 & $113.09722(100)$ & $\begin{array}{l}\mathrm{CH}_{2} \mathrm{O}_{2} \\
\mathrm{H}_{2} \mathrm{O}\end{array}$ \\
\hline Peroxypelargonic acid & & & & $141.09218(3)$ & $\begin{array}{l}\mathrm{CH}_{2} \mathrm{O}_{2} \\
\mathrm{H}_{2} \mathrm{O}\end{array}$ \\
\hline Peroxycapric acid & {$\left[\mathrm{C}_{17} \mathrm{O}_{3}\right]^{-}$} & $173.11827(-0.276)$ & 27 & $155.10776(2)$ & $\begin{array}{l}\mathrm{CH}_{2} \mathrm{O}_{2} \\
\mathrm{H}_{2} \mathrm{O}\end{array}$ \\
\hline
\end{tabular}

Table 2. MS/MS fragmentations of [M-H] $]^{-}$ions from dicarboxylic acids and their peroxyacid analogues. ${ }^{3}$

\begin{tabular}{|c|c|c|c|c|c|}
\hline Compound & $\begin{array}{l}\text { Deprotonated } \\
\text { molecule }[\mathrm{M}-\mathrm{H}]^{-}\end{array}$ & $\begin{array}{l}m / z \\
(\Delta \mathrm{ppm})\end{array}$ & $\begin{array}{l}\text { Collision } \\
\text { energy } \\
(\%)\end{array}$ & $\begin{array}{l}\text { product ion } m / z \\
\text { (rel. abund.) }\end{array}$ & neutral loss(es) \\
\hline Suberic acid & {$\left[\mathrm{C}_{8} \mathrm{H}_{13} \mathrm{O}_{4}\right]^{-}$} & $173.08164(-1.688)$ & 24 & $\begin{array}{l}111.08150(100) \\
129.09208(3)\end{array}$ & $\begin{array}{l}\mathrm{CH}_{2} \mathrm{O}_{3} \\
\mathrm{CO}_{2}\end{array}$ \\
\hline Azelaic acid & {$\left[\mathrm{C}_{9} \mathrm{H}_{15} \mathrm{O}_{4}\right]^{-}$} & $187.09719(-2.097)$ & 25 & $125.09713(100)$ & $\mathrm{CH}_{2} \mathrm{O}_{3}$ \\
\hline Sebacic acid & {$\left[\mathrm{C}_{10} \mathrm{H}_{17} \mathrm{O}_{4}\right]^{-}$} & $201.11277(-2.299)$ & 24 & $\begin{array}{l}139.11286(100) \\
183.10270(34)\end{array}$ & $\begin{array}{l}\mathrm{CH}_{2} \mathrm{O}_{3} \\
\mathrm{H}_{2} \mathrm{O}\end{array}$ \\
\hline Camphoric acid & {$\left[\mathrm{C}_{10} \mathrm{H}_{15} \mathrm{O}_{4}\right]^{-}$} & $199.09721(-1.870)$ & 22 & $155.10767(100)$ & $\mathrm{CO}_{2}$ \\
\hline $\begin{array}{l}\text { Monoperoxysuberic } \\
\text { acid }\end{array}$ & {$\left[\mathrm{C}_{8} \mathrm{H}_{13} \mathrm{O}_{5}\right]^{-}$} & $189.07655(-1.570)$ & 25 & $\begin{array}{l}127.07639(100) \\
143.07133(22) \\
171.06613(8) \\
109.06588(3) \\
145.08694(3)\end{array}$ & $\begin{array}{l}\mathrm{CH}_{2} \mathrm{O}_{3} \\
\mathrm{CH}_{2} \mathrm{O}_{2} \\
\mathrm{H}_{2} \mathrm{O} \\
\mathrm{CH}_{4} \mathrm{O}_{4} \\
\mathrm{CO}_{2}\end{array}$ \\
\hline $\begin{array}{l}\text { Monoperoxyazelaic } \\
\text { acid }\end{array}$ & {$\left[\mathrm{C}_{9} \mathrm{H}_{15} \mathrm{O}_{5}\right]^{-}$} & $203.09207(-2.102)$ & 25 & $\begin{array}{l}141.09205(100) \\
157.08688(19) \\
185.08181(16) \\
123.08150(5)\end{array}$ & $\begin{array}{l}\mathrm{CH}_{2} \mathrm{O}_{3} \\
\mathrm{CH}_{2} \mathrm{O}_{2} \\
\mathrm{H}_{2} \mathrm{O} \\
\mathrm{CH}_{4} \mathrm{O}_{4}\end{array}$ \\
\hline $\begin{array}{l}\text { Monoperoxysebacic } \\
\text { acid }\end{array}$ & {$\left[\mathrm{C}_{10} \mathrm{H}_{17} \mathrm{O}_{5}\right]^{-}$} & $217.10757(-2.657)$ & 25 & $\begin{array}{l}155.10761(100) \\
199.09746(30) \\
171.10251(16) \\
137.09716(12) \\
181.08687(4)\end{array}$ & $\begin{array}{l}\mathrm{CH}_{2} \mathrm{O}_{3} \\
\mathrm{H}_{2} \mathrm{O} \\
\mathrm{CH}_{2} \mathrm{O}_{2} \\
\mathrm{CH}_{4} \mathrm{O}_{4} \\
2 \mathrm{H}_{2} \mathrm{O}\end{array}$ \\
\hline $\begin{array}{l}\text { Monoperoxycamphoric } \\
\text { acid }\end{array}$ & {$\left[\mathrm{C}_{10} \mathrm{H}_{15} \mathrm{O}_{5}\right]^{-}$} & $215.09211(-1.799)$ & 22 & $\begin{array}{l}153.09199(100) \\
154.09974(9) \\
111.08152(7) \\
125.09715(4)\end{array}$ & $\begin{array}{l}\mathrm{CH}_{2} \mathrm{O}_{3} \\
\mathrm{CHO}_{3} \\
\mathrm{C}_{3} \mathrm{H}_{4} \mathrm{O}_{4} \\
\mathrm{C}_{2} \mathrm{H}_{2} \mathrm{O}_{4}\end{array}$ \\
\hline
\end{tabular}

${ }^{2}$ Only product ions with an abundance $\geq 1.0 \%$ relative to the main product ion are listed.

${ }^{3}$ The data shown were averaged from two spectra measured with an isolation width of 1.5.

${ }^{4}$ Only product ions with an abundance $\geq 1.0 \%$ relative to the main product ion are listed. 


\begin{tabular}{|c|c|c|c|c|c|}
\hline & & & & $\begin{array}{l}127.11280(3) \\
138.06862(2)\end{array}$ & $\begin{array}{l}2 \mathrm{CO}_{2} \\
\mathrm{C}_{2} \mathrm{H}_{5} \mathrm{O}_{3}\end{array}$ \\
\hline Diperoxysuberic acid & {$\left[\mathrm{C}_{8} \mathrm{H}_{13} \mathrm{O}_{6}\right]^{-}$} & $205.07146(-1.470)$ & 23 & $\begin{array}{l}143.07130(100) \\
187.06103(38) \\
97.06585(15) \\
188.06884(14) \\
159.06618(4) \\
125.06072(3) \\
171.06613(1)\end{array}$ & $\begin{array}{l}\mathrm{CH}_{2} \mathrm{O}_{3} \\
\mathrm{H}_{2} \mathrm{O} \\
\mathrm{C}_{2} \mathrm{H}_{4} \mathrm{O}_{5} \\
\mathrm{OH} \\
\mathrm{CH}_{2} \mathrm{O}_{2} \\
\mathrm{CH}_{4} \mathrm{O}_{4} \\
\mathrm{H}_{2} \mathrm{O}_{2}\end{array}$ \\
\hline Diperoxyazelaic acid & {$\left[\mathrm{C}_{9} \mathrm{H}_{15} \mathrm{O}_{6}\right]^{-}$} & $219.08704(-1.695)$ & 27 & $\begin{array}{l}157.08691(100) \\
202.08454(64) \\
111.08153(43) \\
201.07679(35) \\
185.08184(14) \\
173.08182(9) \\
139.07646(7) \\
183.06618(1) \\
155.07136(1)\end{array}$ & $\begin{array}{l}\mathrm{CH}_{2} \mathrm{O}_{3} \\
\mathrm{OH} \\
\mathrm{C}_{2} \mathrm{H}_{4} \mathrm{O}_{5} \\
\mathrm{H}_{2} \mathrm{O} \\
\mathrm{H}_{2} \mathrm{O}_{2} \\
\mathrm{CH}_{2} \mathrm{O}_{2} \\
\mathrm{CH}_{4} \mathrm{O}_{4} \\
2 \mathrm{H}_{2} \mathrm{O} \\
\mathrm{CH}_{4} \mathrm{O}_{3}\end{array}$ \\
\hline Diperoxysebacic acid & {$\left[\mathrm{C}_{10} \mathrm{H}_{17} \mathrm{O}_{6}\right]^{-}$} & $233.10270(-1.551)$ & 27 & $\begin{array}{l}171.10251(100) \\
216.10017(31) \\
215.09241(21) \\
125.09715(16) \\
199.09749(13) \\
153.09203(6) \\
197.08186(3) \\
187.09748(3)\end{array}$ & $\begin{array}{l}\mathrm{CH}_{2} \mathrm{O}_{3} \\
\mathrm{OH} \\
\mathrm{H}_{2} \mathrm{O} \\
\mathrm{C}_{2} \mathrm{H}_{4} \mathrm{O}_{5} \\
\mathrm{H}_{2} \mathrm{O}_{2} \\
\mathrm{CH}_{4} \mathrm{O}_{4} \\
2 \mathrm{H}_{2} \mathrm{O} \\
\mathrm{CH}_{2} \mathrm{O}_{2}\end{array}$ \\
\hline
\end{tabular}

\section{CONCLUSIONS}

We have synthesized and characterized 12 peroxy acids, as proxies for a key compound class present in atmospheric aerosol particles, which could play a significant role in the formation processes of organic aerosol particles (e.g. so-called highly oxidized molecules, HOMs) and in their health effects (so-called reactive oxygen species, ROS). In recent years ROS and HOMs have gained significant attention in atmospheric science but due to the lack of available commercial standards the unambiguous identification of the involved compounds remains often uncertain and speculative.

We have shown here that the 12 synthesized peroxy acids can be distinguished from the corresponding carboxylic acids via their MS/MS fragmentation behavior. This is the first time that the fragmentation patterns of aliphatic peroxy acids were investigated systematically. We found characteristic fragmentation patterns for linear peroxymonocarboxylic acids, monoperoxydicarboxylic acids and diperoxydicarboxylic acids. They could be used to distinguish between these three different types of peroxy acids in a prognostic way when characterizing complex organic mixtures containing unknown peroxy acids, such as atmospheric aerosols, but also other environmental samples or in industrial applications.

In addition, a neutral loss of $\mathrm{CH}_{2} \mathrm{O}_{2}$ was observed for all ten linear peroxy acids and could therefore serve as a general indicator for peroxy acid functional groups in these types of compounds. However, the only measured cyclic monoperoxydicarboxylic acid showed fragmentation behavior different from the linear compounds. This indicates the need for further studies of cyclic peroxy acids to establish their characteristic fragmentation patterns, as cyclic peroxy acids are expected to form in the atmosphere in significant amounts, for example through oxidation of terpenes. ${ }^{7,40}$

\section{ASSOCIATED CONTENT}

\section{Supporting Information}

Supporting Information Available:

Figures S-1 to S-4 and Table S-1 (PDF)

This material is available free of charge via the Internet at http://pubs.acs.org.

\section{AUTHOR INFORMATION}




\section{Corresponding Author}

* E-mail: markus.kalberer@atm.ch.cam.ac.uk

\section{Present Addresses}

§Now at: Department of Chemistry and Environmental Research Institute, University College Cork, Cork, Ireland

\section{Author Contributions}

SS and MK planned the experiments. SS performed the experiments with the help of IK. SS wrote the manuscript with contributions of IK and MK. All authors have given approval to the final version of the manuscript.

Notes

The authors declare no competing financial interest.

\section{ACKNOWLEDGEMENTS}

This work was supported by ERC grant no. 279405. S.S.S. acknowledges support from the Swiss National Science Foundation (project no. 162258). The authors would like to thank David R. Spring and Jamie E. Stokes for helpful discussions regarding the peroxy acid syntheses and for provision of safety equipment.

\section{REFERENCES}

(1) Brunekreef, B.; Holgate, S. T. Lancet 2002, 360, $1233-$ 1242.

(2) Dockery, D. W.; Pope, C. A.; Xu, X.; Spengler, J. D.; Ware, J. H.; Fay, M. E.; Ferris, B. G.; Speizer, F. E. N. Engl. J. Med. 1993, 329, 1753-1759.

(3) Nel, A. Science 2005, 308, 804-806.

(4) Dellinger, B.; Pryor, W. A.; Cueto, R.; Squadrito, G. L.; Hegde, V.; Deutsch, W. A. Chem. Res. Toxicol. 2001, 14, 1371-1377.

(5) Donaldson, K.; Stone, V.; Borm, P. J. A.; Jimenez, L. A.; Gilmour, P. S.; Schins, R. P. F.; Knaapen, A. M.; Rahman, I.; Faux, S. P.; Brown, D. M.; MacNee, W. Free Radic. Biol. Med. 2003, 34, 1369-1382.

(6) Kramer, A. J.; Rattanavaraha, W.; Zhang, Z.; Gold, A.; Surratt, J. D.; Lin, Y.-H. Atmos. Environ. 2016, 130, 211-218.

(7) Reinnig, M. C.; Warnke, J.; Hoffmann, T. Rapid Commun. Mass Spectrom. 2009, 23, 1735-1741.

(8) Venkatachari, P.; Hopke, P. K. J. Environ. Monit. 2008, 10, 966-974

(9) Ehn, M.; Thornton, J. a; Kleist, E.; Sipilä, M.; Junninen, H.; Pullinen, I.; Springer, M.; Rubach, F.; Tillmann, R.; Lee, B.; Lopez-Hilfiker, F.; Andres, S.; Acir, I.-H.; Rissanen, M.; Jokinen, T.; Schobesberger, S.; Kangasluoma, J.; Kontkanen, J.; Nieminen, T.; Kurtén, T.; Nielsen, L. B.; Jørgensen, S.; Kjaergaard, H. G.; Canagaratna, M.; Maso, M. D.; Berndt, T.; Petäjä, T.; Wahner, A.; Kerminen, V.-M.; Kulmala, M.; Worsnop, D. R.; Wildt, J.; Mentel, T. F. Nature 2014, 506, 476479.

(10) Rissanen, M. P.; Kurtén, T.; Sipilä, M.; Thornton, J. A.; Kangasluoma, J.; Sarnela, N.; Junninen, H.; Jørgensen, S.; Schallhart, S.; Kajos, M. K.; Taipale, R.; Springer, M.; Mentel, T. F.; Ruuskanen, T.; Petäjä, T.; Worsnop, D. R.; Kjaergaard, H. G.; Ehn, M. J. Am. Chem. Soc. 2014, 136, 15596-15606.

(11) Krow, G. R. Org. React. 1993, 43, 251-798.

(12) Holah, J. T.; Higgs, C.; Robinson, S.; Worthington, D.;
Spenceley, H. Lett. Appl. Microbiol. 1990, 11, 255-259. Kitis, M. Environ. Int. 2004, 30, 47-55.
(13) Milne, N. J. J. Surfactants Deterg. 1998, 1, 253-261. Ramirez, J. A. In Disinfection and decontamination: Principles, applications and related issues; Manivannan, G., Ed.; CRC press: Boca Raton, 2008; pp 73-86.

Reinhardt, G.; Borchers, G. In Handbook of detergents, part E: applications; Zoller, U., Ed.; CRC Press: Boca Raton, 2009; Vol. 141, pp 375-418.

Greenspan, F. P.; MacKellar, D. G. Anal. Chem. 1948, 20, 1061-1063.

Davies, D. M.; Deary, M. E. Analyst 1988, 113, 14771479.

Cairns, G. T.; Diaz, R. R.; Selby, K.; Waddington, D. J. J. Chromatogr. A 1975, 103, 381-384.

Effkemann, S.; Pinkernell, U.; Neumüller, R.; Schwan, F.; Engelhardt, H.; Karst, U. Anal. Chem. 1998, 70, 3857-3862.

Crounse, J. D.; McKinney, K. A.; Kwan, A. J.; Wennberg, P. O. Anal. Chem. 2006, 78, 6726-6732.

Pacenti, M.; Dugheri, S.; Boccalon, P.; Arcangeli, G.; Dolara, P.; Cupelli, V. Ind. Health 2010, 48, 217-221.

Phillips, G. J.; Pouvesle, N.; Thieser, J.; Schuster, G.; Axinte, R.; Fischer, H.; Williams, J.; Lelieveld, J.; Crowley, J. N. Atmos. Chem. Phys. 2013, 13, 11291139.

Ferdousi, B. N.; Islam, M. M.; Okajima, T.; Ohsaka, T. Talanta 2008, 74, 1355-1362.

Stevani, C. V; de Arruda Campos, I. P.; Baader, W. J. J. Chem. Soc. Perkin Trans. 2 1996, No. 8, 1645-1648.

Harman, D. G.; Ramachandran, A.; Gracanin, M.; Blanksby, S. J. J. Org. Chem. 2006, 71, 7996-8005.

Parker, W. E.; Ricciuti, C.; Ogg, C. L.; Swern, D. J. Am. Chem. Soc. 1955, 77, 4037-4041.

Parker, W. E.; Witnauer, L. P.; Swern, D. J. Am. Chem. Soc. 1957, 79, 1929-1931.

Milas, N. A.; McAlevy, A. J. Am. Chem. Soc. 1933, 55, 349-352.

Pirkle, W. H.; Rinaldi, P. L. J. Org. Chem. 1977, 42, 2080-2082.

Mora, J. F. de la; Van Berkel, G. J.; Enke, C. G.; Cole, R. B.; Martinez-Sanchez, M.; Fenn, J. B. J. Mass Spectrom. 2000, 35, 939-952.

Van Berkel, G. J.; McLuckey, S. A.; Glish, G. L. Anal. Chem. 1992, 64, 1586-1593.

Cech, N. B.; Enke, C. G. Mass Spectrom. Rev. 2001, 20 , 362-387.

Kirk, O.; Damhus, T.; Würtz Christensen, M. $J$. Chromatogr. A 1992, 606, 49-53.

Awad, M. I.; Denggerile, A.; Ohsaka, T. J. Electrochem. Soc. 2004, 151, E358.

Štávová, J.; Beránek, J.; Nelson, E. P.; Diep, B. A.; Kubátová, A. J. Chromatogr. B 2011, 879, 1429-1438.

Grossert, J. S.; Fancy, P. D.; White, R. L. Can. J. Chem. 2005, 83, 1878-1890.

Yasmeen, F.; Szmigielski, R.; Vermeylen, R.; GomezGonzález, Y.; Surratt, J. D.; Chan, A. W. H.; Seinfeld, J. H.; Maenhaut, W.; Claeys, M. J. Mass Spectrom. 2011, $46,425-442$.

Glasius, M.; Duane, M.; Larsen, B. R. J. Chromatogr. A 1999, 833, 121-135.

Docherty, K. S.; Wu, W.; Lim, Y. Bin; Ziemann, P. J. Environ. Sci. Technol. 2005, 39, 4049-4059. 


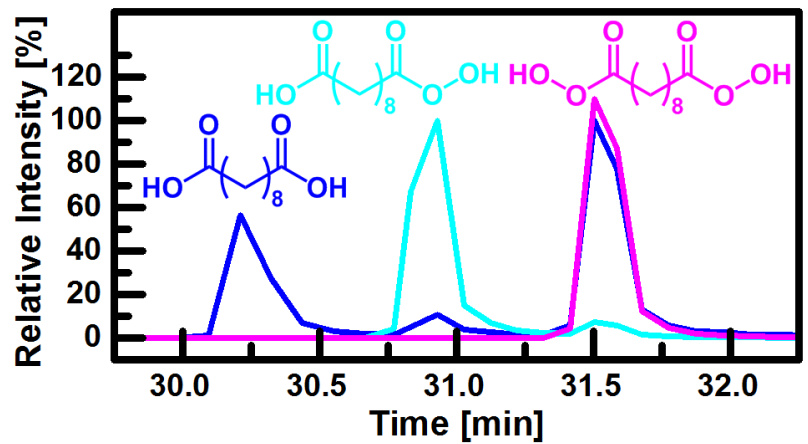

For TOC only 